\title{
Do Insect and Mold Damage Affect Maize Prices in Africa? Evidence from Malawi
}

\author{
Michael Jones, Corinne Alexander, Nicole Olynk Widmar*, Jacob Ricker-Gilbert, \\ Jess M. Lowenberg-DeBoer
}

Department of Agricultural Economics, Purdue University, West Lafayette, IN, USA

Email: *nwidmar@purdue.edu

How to cite this paper: Jones, M., Alexander, C., Widmar, N.O., Ricker-Gilbert, J. and Lowenberg-DeBoer, J.M. (2016) Do Insect and Mold Damage Affect Maize Prices in Africa? Evidence from Malawi. Modern Economy, 7, 1168-1185.

http://dx.doi.org/10.4236/me.2016.711115

Received: August 8, 2016

Accepted: September 23, 2016

Published: September 26, 2016

Copyright $\odot 2016$ by authors and Scientific Research Publishing Inc.

This work is licensed under the Creative Commons Attribution International License (CC BY 4.0).

http://creativecommons.org/licenses/by/4.0/

\begin{abstract}
Economic losses to stored grain can potentially come from both quantity losses and quality losses in the form of price discounts for damage from insects and mold. This article uses choice experiments conducted with physical samples of maize to estimate discounts for damaged grain among maize traders in Malawi. Using the Equality Constrained Latent Class method to correct for non-attendance to the price attribute, we find that traders place a statistically and economically significant discount on insect-damaged maize. We estimate that a $1 \%$ increase in maize damage reduces the price of maize by $2.8 \%$ to $3.6 \%$, depending on damage level. We discuss the implications of these results for farmers' incentives to adopt improved storage technologies that can reduce post-harvest losses.
\end{abstract}

\section{Keywords}

Insect Damaged Maize, Post-Harvest Losses, Choice Experiments, Attribute Non-Attendance, Sub-Saharan Africa

\section{Introduction}

Smallholder post-harvest loss (PHL) for staple grains is a widespread and important problem throughout Sub-Saharan African (SSA). PHL occurs during grain harvesting, transporting, processing, and storage, and is primarily caused by insect pests and mold [1]. For example, the region's most important staple grain, maize is under constant threat from the extremely destructive larger grain borer when it is placed in storage.

PHL creates two major challenges for smallholders. The first challenge is widely recognized; PHL causes quantity loss in the amount of grain that is available to meet household consumption and income needs later in the year. Entomology research suggests that insects like larger grain borer can damage up to $30 \%$ of stored maize over a 
6-month period, unless smallholders have access to improved storage technologies [2] [3]. Economists also recognize the importance of quantity loss as an implicit part of storage costs in models of smallholders' storage behavior [4]-[7].

The second challenge is an economic problem that has received less attention in the literature. Depending upon how the market values grain quality, households may be forced to accept steep price discounts when they sell grain that has been damaged by mold or insects [8]-[10]. The magnitude of these discounts has major ramifications for household income, food security, and the safety of the grain that consumers in SSA eat.

The existence and magnitude of a price discount schedule for damaged maize remains largely unanswered for SSA. This is a critical question because a well-functioning maize market is essential for smallholder households to be food secure. Many smallholders do not produce enough staple crops to meet their consumption needs, and must rely on the market to make up for their own production deficit. For a grain market to function well there needs to be minimum quality standard and a price discount schedule [11]-[13]. Price discounts for low quality grain serve two important economic functions. First, price discounts transmit information about consumer preferences to producers. Second, price discounts incentivize farmers and traders to invest in storage technology to maintain grain quality. The absence of transparent discount schedules that reward high quality grain may lead households to underinvest in effective storage technologies which could mitigate PHL. In addition, households may decide to sell at harvest rather than store because if they are unable to preserve grain quality, the price discounts would erode the inter-temporal price increase. Last, households who do have access to effective storage technologies may choose to self-provision maize of known quality rather than purchase maize of unknown quality from the market [9].

Against this backdrop, our objective is to estimate discount schedules for damaged maize in SSA. We use a choice experiment (CE) incorporated into a survey of smallscale maize traders in rural Malawi. Malawi is an ideal case study to estimate maize discount schedules because i) as in many other African countries, maize is by far the most produced, traded and consumed grain, accounting for 53\% of available calories [14] and ii) the vast majority of farmers harvest only one time during the year from April to July, so insect damage is a major issue as maize must be kept in storage for many months. In addition, having one growing season and poor infrastructure with high transport costs means that maize prices can increase by up to $100 \%$ between harvest and lean seasons [15].

Several studies have documented significant price discounts from insect damage for common beans in Tanzania [16] and cowpeas in West Africa [17] [18]. However, there is very little literature that estimates discounts for damaged maize in Africa. Compton et al. [19] uses focus groups with traders in Ghana during the 1993/94 season to investigate price discounts for insect-damaged maize and is the only article to estimate a discount schedule for insect damage. Kadjo et al. [10] surveyed farmers in Benin and compares price discounts for insect damaged maize using stated preference and revealed preference methods. The authors find larger price discounts in the early post- 
harvest period when maize is plentiful, compared to later in the lean season when maize is scarce.

Hoffman and Gatobu [9] use a framed field experiment to value maize with the following visible attributes: percent debris, presence of weevils, percent discolored, and percent broken. They find that consumers are willing to pay $20 \%$ more for their own home-grown maize than maize of similar quality from the market. The authors argue that the premium for home-grown maize is the result of consumers' preferences for unobservable quality attributes such as taste and aflatoxin contamination. Aflatoxin contamination is a toxin produced by the mold Aspergillus and while the mold can be visible, the toxin is invisible and tasteless making it unobservable without a scientific test. Hoffman et al. [20] examine the impact of the maize quality attribute of aflatoxin contamination on the resulting price and use of the maize, based on data from over 2000 maize samples in Kenya. They find that the presence of aflatoxin, which is unobservable and therefore a credence attribute, affects the use but not the price of maize.

This article builds upon and extends the previous literature in two main ways. First, the $\mathrm{CE}$ used in this article is conducted in the marketplace with traders actively buying grain, making the occasion and setting, as well as choice, mimic reality as closely as possible. Second, to our knowledge, this article is the first to use choice experiments to evaluate WTP for insect and mold damage in SSA by maize traders. Using the Equality Constrained Latent Class method to correct for non-attendance to the price attribute, results of our study find that traders place a statistically and economically significant discount on insect-damaged maize. We estimate that a $1 \%$ increase in maize damage reduces the price of maize by $2.8 \%$ to $3.6 \%$, depending on damage level.

The rest of the article is organized as follows. We present the choice experiment and the theoretical framework. We introduce the Equality Constrained Latent Class Approach that is used to estimate trader WTP estimates of discounts for insect and mold damage, data collection and results. Finally, we draw conclusions about the value of formal discount schedules.

\section{Methodology}

\subsection{Choice of Methodology}

In measuring trader WTP for grain quality, there are several possible approaches. One possible approach is to use experimental auctions with maize of different qualities. However, maize traders do not operate in auction-settings; maize traders are buying and selling in one-on-one individual transactions in the marketplace. Furthermore, the development of auctions was cost prohibitive to construct enough samples to auction for this study. A second possible approach is to use revealed preference data by purchasing maize in the market and evaluating the relationship between maize price and quality using hedonic methods. The advantage of this approach is that it is consequential. However, the major disadvantages are that the information about maize quality is limited to the observed maize quality in the market which may not include samples of highly damaged maize, and to collect enough data often takes several years. A third 
possible approach is choice experiment (CE) and given the market setting in which traders operate in Malawi, as well as the transactions themselves, the $\mathrm{CE}$ is the best fit for the research question, geography, and decision makers involved. The validity of CEs using SP data to estimate attribute valuations of agricultural products is well documented in previous literature [21] [22].

\subsection{Choice Experiment}

The objective of our CE is to evaluate Malawian maize traders' WTP for maize attributes. Lancaster [23] argues that utility is not necessarily derived from a good itself; rather, utility is gained from the individual attributes composing a good. In this context maize is viewed as a collection of variety and quality maize attributes which are heterogeneously valued by Malawian maize traders.

The $\mathrm{CE}$ used in this article is administered according to the following procedure. We create a realistic purchasing scenario, by conducting in the market on a market day when maize is frequently bought and sold. By approaching working maize traders in the market, we know they have experience visually evaluating and buying maize. Each trader is approached individually because when a trader purchases grain from a farmer, they negotiate one-on-one to agree on a price. We offer the traders physical samples of maize that had different levels of insect and mold damage. No payment is requested for the samples. The maize samples, each comprised of one kilogram $(\mathrm{kg})$ of maize, are placed in clear, gallon-size $(3.78 \mathrm{~L})$ Ziploc $^{\circledast}$ Slide-Lock bags. The price per $\mathrm{kg}$ of maize is clearly labeled on each bag, and the enumerator also verbally reports the price to assure understanding. The price level is designated as the final buying price after any negotiation $^{1}$. CEs are generally administered through written descriptions of attribute variables which are presented in an internet survey [24], mail [25], or an on-site survey [26]. Written descriptions are advantageous when respondents are educated, literate and can independently assess attributes between alternatives. However, low education levels and illiteracy may prohibit unaided responses to written surveys. For our target population of maize traders in Malawi, we hired enumerators to conduct the CE in the local language.

One common weakness of choice experiments is that WTP estimates can be overestimated due to the hypothetical nature of the experiment, as compared to purchasing situations in which budgetary constraints are recognized and taken into account explicitly. Investigating more specific non-hypothetical product attributes, such as maize insect damage levels, may require physical interaction with the actual product to accurately simulate a purchasing experience [27]. Compton et al. [19] follow this protocol in focus groups with maize traders and note they tend to physically examine maize samples before valuation, as one would in a real purchasing scenario. In our CE, traders are shown a series of two one-kg samples of maize with varying attribute levels for price, variety, insect damage, and mold damage. For example, a choice bag could contain a

${ }^{1}$ Negotiation is typical between maize traders and farmers, and thus it is important to specify that the labeled prices are post negotiation. Compton et al. [19] similarly designate post-negotiation prices with Ghanaian traders. 
hybrid maize variety called DK8033, of which $5 \%$ of grains have (only) mold damage, $30 \%$ have (only) insect damage, and $65 \%$ are undamaged kernels. The other choice bag could contain a local variety maize, of which $0 \%$ of grains have mold damage, $10 \%$ have (only) insect damage, and $90 \%$ are undamaged kernels. They are encouraged to remove contents for further examination since they must visually discern the variety, insect damage and mold damage attributes of each sample. Many of the traders did remove the maize for closer inspection. They are asked to evaluate each set of samples as if they are negotiating with a farmer who has two maize samples to sell. Traders are then asked to indicate their preferred sample, or if they would "opt-out" from purchasing either of the two samples.

\subsection{Choice Experiment Attributes and Levels}

Quality attributes of insect damage, mold damage and maize variety are incorporated since they are highlighted in the literature as influential or potentially influential in price formation. Insect damage is the primary attribute of interest, and the most significant post-harvest problem for maize in Malawi. The larger grain borer is the most destructive of the storage insects common in Malawi, and it causes an average 5\%-10\% dry weight loss over 6 - 8 months of storage [2]. This 5\% - 10\% dry weight loss translates to about $22 \%-40 \%$ damaged grain [28]. Therefore, $30 \%$ and $20 \%$ insect damage levels were chosen as reasonable estimates of grain damage rates with no or very low insecticide use [29] [30]. Roughly $2 \%$ - 3\% dry weight loss translates to $10 \%$ damaged grains [28] which is a reasonable estimate for damage with standard insecticides available to Malawian farmers [30] [31]. The near or complete absence of grain damage would be rare, though technically possible with high doses of insecticides or hermetic storage. Therefore, $0 \%, 10 \%, 20 \%$, and $30 \%$ insect damage were chosen to represent a reasonable range of damage which could be presented to traders ${ }^{2}$.

Mold damage is tested at $5 \%$ grains with visible mold damage based on interviews with extension personnel. The Malawian maize harvest occurs in the dry season, allowing producers to effectively solar-dry maize to safe storage moistures which greatly reduce the potential for mold development. Extension officials indicate that mold is much less of a storage constraint than insects, and thus this low, yet visually-detectable level is chosen for evaluation in the CE.

Two varietal attribute levels were chosen for our CE, namely local and hybrid. While many regions of SSA have several named local varieties, "local" maize is not further differentiated in Malawi [32]. The hybrid maize selected is DK8033, a widely dispersed dent hybrid that would likely be known to all or most maize traders ${ }^{3}$. Compton et al. [19] did not find notable price differences among varieties in Ghana, however Smale et al. [32], and Lunduka et al. [33] note considerable preference for local maize in Malawi.

Trader preferences for low insect damage may also be influenced by the amount of

${ }^{2}$ Rounding at standard increments of $10 \%$ also helped ensure accuracy of the volumetric sample construction. This was crucial since we are using physical grain samples for the choice experiment.

${ }^{3}$ We chose to present the most commonly available hybrid, rather than several hybrids, to avoid bias that may arise if traders have preferences for different hybrids. 
time they intend to store the grain before resale. If traders turn over their stored grain quickly, weevils and grain borers burrowed in damaged grain have little time to significantly increase damage levels. However, the exponential growth of insect grain damage could result in dramatic quality losses if grain is left untreated for an extended period of time. We hypothesize that traders who store longer may have stronger preferences for undamaged grain, which may ultimately bias the average grain damage coefficients. Maize price data from the Ministry of Agriculture showed that there are large contemporaneous price differences between markets in districts within the same region. These large price differences may be the result of high transaction costs inhibiting the trade of a relatively low-value good. Thus, using fixed-price attribute levels in the CE would result in respondents in some districts being offered choices with unrealistic price ranges. To contextualize the price variable to district conditions, price levels are established as a relative percentage of the mean buying price in the first-visited market in each district.

Willingness-to-pay Estimation Table 1 summarizes each maize attribute and their levels in the CE. In this context $\boldsymbol{X}_{i j t}$ is a $9 \times 1$ vector of maize attributes,

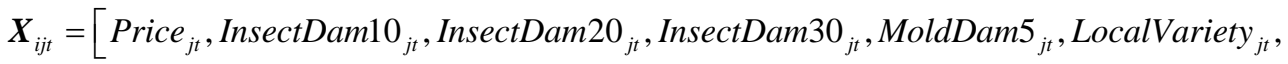

$$
\begin{aligned}
& \left.(\text { InsectDam } 10 * \text { Time })_{j t},(\text { InsectDam } 20 * \text { Time })_{j t},(\text { InsectDam30 * Time })_{j t}\right] \text {. }
\end{aligned}
$$

Non-price maize attributes are effects-coded relative to the maize sample which has no insect damage, no visible mold damage, and is of the hybrid variety DK8033. Effects-coding is performed with insect damage levels (10\%, 20\%, and 30\% damage are represented as InsectDam10, InsectDam20, InsectDam30, respectively), 5\% mold damage (MoldDam5), and the variety variable (LocalVariety) to avoid confounding results between attribute levels and opting out options [21]. In addition the insect damage levels are interacted with the time in months that grain is stored (Time), resulting in three interaction terms. The $\beta$ s in the above-described models are utility parameters to be estimated. Interpretation of individual coefficients is discouraged in random utility models, however, the coefficients can be used to estimate mean WTP and confidence intervals. Willingness-to-pay (WTP) estimates provide information on the marginal rate of substitution between price and each of the physical maize attributes. WTP is given by:

$$
W T P_{m}=-\frac{2 \beta_{m}}{\alpha}
$$

Table 1. Maize variety and quality attributes evaluated.

\begin{tabular}{ccc}
\hline Attribute & Levels & Description \\
\hline Price & $-20 \%,-10 \%$, mean $,+10 \%,+20 \%$ & Relative to mean buying price in the market \\
Insect damage & $0 \%, 10 \%, 20 \%, 30 \%$ & $(\%)$ of grains with visible insect damage \\
Mold presence & $0 \%, 5 \%$ & $(\%)$ of grains with visible mold \\
Variety & "Local", Hybrid (Dent, DK8033) & Local is a "flint" variety and \\
\end{tabular}


where $W T P_{m}$ is the willingness-to-pay for the $m$ th attribute, $\beta_{m}$ is the estimated utility parameter for the $m$ th attribute, and $\alpha$ is the estimated price coefficient. Since effects coding is used, the WTP calculation is multiplied by two [21]. The delta method is used in this analysis to estimate confidence intervals on WTP estimates; the delta method takes a first order Taylor series expansion around the mean value of the variables and calculates the variance for this expression [34] [35] $]^{4}$.

A fractional factorial experimental design is constructed through the OPTEX procedure in SAS to identify an experimental design maximizing D-efficiency (78.99). The total of 30 choice sets to be presented were randomly blocked into three groups of ten to keep the choice task reasonable for respondents [36] [37]. Each block contains a total of $20 \mathrm{~kg}$ of maize and is transported in a rolling suitcase with segmented compartments.

\section{Theoretical Framework}

\subsection{Random Utility Theory}

Random utility theory assumes that economic actors seek to maximize their expected utility subject to the alternatives, or choice set, they are presented. Based on Manski [38], an individual's utility is a random variable because the researcher has incomplete information. Choice experiments assume an individual $(i)$ maximizes utility $(U)$ attained from an alternative $(j)$ at choice scenario [time] $(t)$. Utility is composed of both a deterministic $V\left(\boldsymbol{X}_{i j t}\right)$ and stochastic elements $\left(\varepsilon_{i j t}\right)$, represented here as:

$$
U_{i j t}=V\left(\boldsymbol{X}_{i j t}\right)+\varepsilon_{i j t} \text {. }
$$

An individual facing a choice between two alternatives $j$ and $k$ is assumed to optimize his or her utility, represented by $\pi$, such that probability of choosing $j$ is:

$$
\pi_{i t}(j)=\operatorname{Prob}\left\{V\left(\boldsymbol{X}_{i j t}\right)+\varepsilon_{i j t} \geq V\left(\boldsymbol{X}_{i k t}\right)+\varepsilon_{i k t} ; j \neq k\right\} .
$$

In this context, $\boldsymbol{X}_{i j t}$ is a vector of product attributes and $\varepsilon_{i j t}$ is the random error term iid over all individuals, alternatives and choice situations [39]. The deterministic component of utility $V\left(\boldsymbol{X}_{i j t}\right)$ is assumed to be linear in parameters and the functional form for the deterministic component can be expressed as:

$$
V_{i j t}=\beta^{\prime} \boldsymbol{X}_{i j t} .
$$

Models which account for heterogeneity in preferences, namely the latent class model (LCM) and random parameters logit model (RPL), are widely used in applied research, as they provide a valuable tool to measure diversity which exists in the marketplace. This article utilizes the LCM to discretely estimate heterogeneity in attribute valuation.

\subsection{Latent Class Model}

In LCMs, (i) individuals are intrinsically sorted into $S$ latent classes for which they have

${ }^{4}$ There are various methods available, and commonly used, to estimate confidence intervals for WTP estimates including the delta, Fieller, Krinsky-Robb, and bootstrap methods. Hole [35] found these methods to be reasonably accurate and yield similar results to one another. 
the greatest probability of membership [40]. Heterogeneous preferences are assumed between classes and homogeneous preferences are assumed within each class [41]. Individuals are probabilistically assigned to classes, and utility parameters are estimated for each class.

The LCM is an extension of the traditional multinomial logit model (MNL), which states that the probability of an individual choosing $j$ takes the form:

$$
\pi_{i t}(j)=\frac{\exp \left[\mu\left(\beta^{\prime} X_{i j t}\right)\right]}{\sum_{j=1}^{J} \exp \left[\mu\left(\beta^{\prime} X_{i j t}\right)\right]}
$$

where $\mu$ is a scale parameter inversely related to variance of the error term, assumed equivalent to 1 within any dataset. Building on MNL, the LCM incorporates $S$ number of discrete $\beta$ values with utility expressed as $V_{i j t s}=\alpha_{s}^{\prime} P_{i t}+\beta_{s}^{\prime} X_{i j t}+\varepsilon_{i j t \mid s}$ [41]. Equation (11) then becomes:

$$
\pi_{i t \mid s}(j)=\sum_{s=1}^{s} \frac{\exp \left[\mu_{s}\left(\beta_{s}^{\prime} X_{i j t}\right)\right]}{\sum_{j=1}^{J} \exp \left[\mu_{s}\left(\beta_{s}^{\prime} X_{i j t}\right)\right]} R_{i s}
$$

where $\beta_{s}$ is vector of parameters for class $s$, and $R_{i s}$ is the probability that individual $(i)$ is sorted into class $s$.

\subsection{Attribute Non-Attendance and Equality Constrained Latent Class Approach}

In CEs, respondents are asked to choose from amongst provided alternatives, each alternative for which they are provided a bundle of attributes. An assumption of unlimited substitutability between the attributes used to describe the alternatives provided gives rise to the continuity axiom and implies that respondents make trade-offs between all attributes described to choose their most preferred alternative in the choice set [42]. Attribute non-attendance (ANA) occurs when respondents ignore specific attributes when choosing between alternatives [42] [43]. Of particular concern when calculating WTP is when respondents do not take into account the "price" attribute. When simply proceeding with a model which does not account for this effect, inflated WTP estimates may lead to improper policy recommendations.

The Equality Constrained Latent Class (ECLC) uses a latent class approach to algorithmically group individuals according to their patterns of attribute attendance [42]. Scarpa et al. [42] measure total attendance, total non-attendance, all single attribute non-attendance, and dual attribute non-attendance of price with non-price attributes. We approach the ECLC by creating three latent classes-total attendance, total nonattendance, and partial non-attendance of the price attribute. Total non-attendance must be accounted for to remove any individuals who chose haphazardly and may bias estimation of coefficients. Partial non-attendance must be treated in context with the experiment design. In this article, non-price attributes are not disclosed in written form to traders, therefore discernment of maize attributes is performed individually. As such, 
non-attendance to certain non-price attributes is plausible and acceptable; attributes such as maize variety may in fact carry no importance to the respondent ${ }^{5}$.

\subsection{Data Collection}

Maize traders were surveyed in January and February 2012 in five districts, drawn from all three regions of Malawi; Thyolo and Zomba in the Southern Region, Lilongwe and Nkhotakota in the Central Region, and Mzimba in the Northern Region. We selected districts to maximize geographic diversity of sampling with reasonable approximations for key maize production areas, marketing, and post-harvest management statistics, as determined from nationally representative data from the Ministry of Agriculture and Food Security (2009) Agricultural Input Subsidy Survey [44] [45]. According to the 2008 national census, the Central and Southern Regions contain 87\% of the national population, motivating the larger proportion of districts from these regions in the sample [44]. Roughly two-thirds of traders approached agreed to participate in the survey. In total, valid surveys were collected from 252 maize traders across these markets.

Many traders in Malawi travel to villages to purchase maize on farm, or they allow farmers to assume transportation costs and approach them in markets to buy their grain [46]. Maize markets generally function as daily or weekly trading centers, attracting traders of diverse sizes [46]. In our survey, a minimum of 50 traders per district were sampled in maize markets on official market days. This gives us the benefit of conducting the valuation in a setting where actual purchases occur, a factor determined influential in helping respondents make realistic choices [47]. At least three markets were sampled in each district, including at least one major and one minor market. As the focus of this study was in markets, we have potentially excluded rural assemblers who are not present on market days. One should note that these assemblers and other traders not operating within markets may have different characteristics than those traders within markets (such as being disproportionately male). Therefore these results should be interpreted as applying to maize traders who buy and sell within maize markets.

Random sampling of all district markets was not possible due to daily trader movement and severe national fuel shortages that prevented sampling of remote markets. Two Malawian university graduates were hired and trained as survey enumerators to conduct this experiment in Chichewa, the dominant local language. While the surveying procedures described were employed to obtain a random sampling which was representative of Malawi market traders, it is acknowledged that numerous demographic and trader-specific factors (i.e. experience level, past experience with enumerators, personality) may influence willingness to participate in the survey and experiment. Thus, while careful sampling procedures were employed, the authors acknowledge the ever-present risk of sample selection bias.

${ }^{5}$ ANA was also investigated by a coefficient of variation approach popularized by Hess and Hensher [48]. Results confirm the presence of ANA in the price attribute and variety attribute (though varietal indifference is plausible and allowable in this context). ANA is not of concern in the mold or insect damage attributes. These results help confirm the structure of the ECLC classes selected here. Results available from the authors upon request. 


\section{Results}

Detailed descriptive statistics for traders surveyed are presented in Table 2. The overall sample is balanced in gender and age. Females have an average 2.9 more years of experience trading maize, but operate in fewer districts and markets. Male traders sell about four times the quantity of maize as females and are more than twice as likely to use a truck when sourcing grain. In the previous marketing season (2010/11), traders sourced about $80 \%$ of their stocks in the "Harvest months" between April and July, about $12.3 \%$ between August and November, and only 6.7\% of stocks in the "Lean Season" months from December to March. In the 2011/12 marketing season, traders report more balanced purchasing throughout the marketing season. These differences in the timing of trader purchases may reflect price patterns and farmer willingness-to-sell at market prices, as prices declined throughout the 2010/11 marketing season but rose dramatically throughout the 2011/12 season. The average trader stores maize sourced during the harvest season for 2.5 months, compared to 1.3 months for maize sourced during the mid-season and 0.5 months for maize sourced during the lean season. On average, men store almost one month longer than women. Male and female traders report significantly different marketing margins of $22.1 \%$ and $35.2 \%$, respectively. Marketing margins may be related to the scale of trade, as most women sell much smaller quantities per transaction.

We use the ECLC methodology to control for price non-attendance. In this CE, the non-price attributes of insect damage, mold damage and variety are not disclosed in

Table 2. Trader descriptive statistics.

\begin{tabular}{|c|c|c|c|}
\hline Demographics & Female $(n=130)$ & Male $(\mathrm{n}=122)$ & Total $(\mathrm{n}=252)$ \\
\hline Age (mean \pm sd) & $36.3 \pm 10.6$ & $29.9 \pm 8.0$ & $33.2 \pm 10.0$ \\
\hline Years of experience (mean $\pm \mathrm{sd}$ ) & $8.5 \pm 7.9$ & $5.6 \pm 4.8$ & $7.1 \pm 6.7$ \\
\hline District(s) trading (mean $\pm \mathrm{sd})$ & $1.1 \pm 0.5$ & $1.7 \pm 1.2$ & $1.4 \pm 1.0$ \\
\hline Quantity sold last year $(\mathrm{kg})($ mean $\pm \mathrm{sd})$ & $10,103 \pm 17,851$ & $172,996 \pm 716,594$ & $90,560 \pm 509,312$ \\
\hline Quantity sold last year (kg) (median) & 3,500 & 15,000 & 6,000 \\
\hline Use truck when sourcing (\%) & 47.3 & 76.2 & 61.4 \\
\hline Prior year maize sourced from farmers (\%) & 72.4 & 67.5 & 70.0 \\
\hline "Lean-season" months (Dec.-Mar.) & 28.1 & 27.6 & 27.8 \\
\hline Current year, months stored after sourced: "Harvest" months (Apr.-July.) (mean \pm sd) & $2.6 \pm 2.5$ & $2.5 \pm 2.3$ & $2.5 \pm 2.4$ \\
\hline "Mid-season" months (Aug.-Nov.) (mean \pm sd) & $1.3 \pm 1.2$ & $1.3 \pm 1.3$ & $1.3 \pm 1.3$ \\
\hline "Lean-season" months (Dec.-Mar.) (mean \pm sd) & $0.4 \pm 0.5$ & $0.7 \pm 1.0$ & $0.5 \pm 0.8$ \\
\hline Reported marketing margin (\%) & 35.2 & 22.1 & 28.7 \\
\hline
\end{tabular}


written form. Thus discernment of maize attributes is performed individually making ANA to non-price attributes plausible and acceptable. We follow the ECLC method by only treating the price attribute which is explicitly revealed. We find total non-attendance represents $3.8 \%$ of the sample and price non-attendance represents $61.8 \%$ of the sample 6 . Rates of ANA to price attributes vary significantly in the literature. Scarpa et al. [42] find that $92 \%$ of their sample does not attend to the price attribute. For comparison, Widmar and Ortega [49] investigate various criteria for ANA using coefficients of variation and find rates as low as $8 \%$ ANA to price when using a cutoff of three and as high as $35 \%$ when using a cutoff of one.

Table 3 presents the results for the ECLC model that corrects for price non-attendance. Traditionally, WTP estimates are given in currency units. The structure of the

Table 3. Malawian trader willingness to pay for maize quality results with the Equality Constrained Latent Class Model (ECLC).

\begin{tabular}{|c|c|c|c|c|}
\hline \multirow[b]{2}{*}{ Attributes } & \multicolumn{2}{|c|}{ Multinomial logit model } & \multicolumn{2}{|c|}{ ECLC adjusted model } \\
\hline & $\begin{array}{c}\hat{\beta} \\
\text { (st. err.) }\end{array}$ & $\begin{array}{c}\widehat{W T P} \\
{[95 \% \mathrm{CI}]}\end{array}$ & $\begin{array}{c}\hat{\beta} \\
\text { (st. err.) }\end{array}$ & $\begin{array}{c}\widehat{W T P} \\
{[95 \% \mathrm{CI}]}\end{array}$ \\
\hline $\begin{array}{l}\text { Local variety } \\
\text { (vs. hybrid) }\end{array}$ & $\begin{array}{c}0.28^{\star * *} \\
(0.03)\end{array}$ & $\begin{array}{c}0.64 \\
{[0.44,0.85]}\end{array}$ & $\begin{array}{c}0.36^{\star * *} \\
(0.04)\end{array}$ & $\begin{array}{c}0.22 \\
{[0.19,0.24]}\end{array}$ \\
\hline Mold at 5\% level (vs. $0 \%$ ) & $\begin{array}{c}-0.55^{\star * *} \\
(0.03)\end{array}$ & $\begin{array}{c}-1.29 \\
{[-1.68,-0.90]}\end{array}$ & $\begin{array}{c}-0.70^{\star * *} \\
(0.05)\end{array}$ & $\begin{array}{c}-0.42 \\
{[-0.45,-0.39]}\end{array}$ \\
\hline $10 \%$ grain damage (vs. $0 \%$ ) & $\begin{array}{c}-0.51^{\star * *} \\
(0.05)\end{array}$ & $\begin{array}{c}-1.18 \\
{[-1.54,-0.82]}\end{array}$ & $\begin{array}{c}-0.60^{\star * *} \\
(0.07)\end{array}$ & $\begin{array}{c}-0.36 \\
{[-0.40,-0.32]}\end{array}$ \\
\hline $20 \%$ grain damage (vs. $0 \%$ ) & $\begin{array}{c}-0.88^{\star * *} \\
(0.06)\end{array}$ & $\begin{array}{c}-2.05 \\
{[-2.66,-1.45]}\end{array}$ & $\begin{array}{c}-1.07^{\star * *} \\
(0.07)\end{array}$ & $\begin{array}{c}-0.65 \\
{[-0.69,-0.60]}\end{array}$ \\
\hline $30 \%$ grain damage (vs. $0 \%$ ) & $\begin{array}{c}-1.16^{\star *} \\
(0.06)\end{array}$ & $\begin{array}{c}-2.69 \\
{[-3.45,-1.93]}\end{array}$ & $\begin{array}{c}-1.40^{* *} \\
(0.09)\end{array}$ & $\begin{array}{c}-0.85 \\
{[-0.90,-0.79]}\end{array}$ \\
\hline $10 \%$ grain damage $\times$ time stored $(\mathrm{m})$ & $\begin{array}{c}-0.14^{* * *} \\
(0.05)\end{array}$ & $\begin{array}{c}-0.32 \\
{[-0.47,-0.17]}\end{array}$ & $\begin{array}{c}-0.22^{\star * *} \\
(0.06)\end{array}$ & $\begin{array}{c}-0.13 \\
{[-0.17,-0.10]}\end{array}$ \\
\hline $20 \%$ grain damage $\times$ time stored $(\mathrm{m})$ & $\begin{array}{l}-0.03 \\
(0.05)\end{array}$ & $\begin{array}{c}-0.07 \\
{[-0.19,0.05]}\end{array}$ & $\begin{array}{c}-0.12^{\star} \\
(0.07)\end{array}$ & $\begin{array}{c}-0.07 \\
{[-0.11,-0.03]}\end{array}$ \\
\hline $30 \%$ grain damage $\times$ time stored $(\mathrm{m})$ & $\begin{array}{c}-0.18^{\star * *} \\
(0.05)\end{array}$ & $\begin{array}{c}-0.42 \\
{[-0.59,-0.25]}\end{array}$ & $\begin{array}{c}-0.32^{\star * *} \\
(0.08)\end{array}$ & $\begin{array}{c}-0.19 \\
{[-0.24,-0.14]}\end{array}$ \\
\hline Opt out & $\begin{array}{l}0.49^{\star *} \\
(0.25)\end{array}$ & $\begin{array}{c}1.14 \\
{[0.25,2.04]}\end{array}$ & $\begin{array}{l}0.25^{\star} \\
(0.14)\end{array}$ & $\begin{array}{c}0.08 \\
{[-0.01,0.16]}\end{array}$ \\
\hline Price & $\begin{array}{c}-0.86^{* * *} \\
(0.25)\end{array}$ & & $\begin{array}{c}-3.32^{* * *} \\
(0.14)\end{array}$ & \\
\hline Log-likelihood & -2231.05 & & -1932.20 & \\
\hline Pseudo- $\mathrm{R}^{2}$ & 0.19 & & 0.30 & \\
\hline
\end{tabular}

Note: $95 \%$ confidence intervals are in brackets and derived by the Delta method [35]. Note: ${ }^{*}{ }^{* *}$ and ${ }^{* *}$ indicate significance at the $10 \%, 5 \%$, and $1 \%$ level, respectively.

${ }^{6}$ Various potential relationships can be explored with regard to identification of relationships between trader demographics or characteristics and ANA. Relationships are investigated by correlating individual-specific coefficient estimates and key characteristics collected in the survey. Relationships to non-attendance robust to model specification identified are increased full ANA among low-educated traders and decreased full ANA among first-year traders. First year traders may be particularly inclined to focus on price compared to more experienced traders, contributing to lower ANA. Low-educated traders may have decreased consistency within their choices, driving full ANA; this finding matches results of Jones et al. [50] in which low-educated US consumers had significantly higher preference transitivity violations in a CE. Further, female maize traders had slightly increased combined full and price ANA. 
price variable in this experiment requires that WTP estimates are interpreted as the percentage price differential between each attribute. For example, the WTP for local variety maize in the ECLC model is interpreted as a $22 \%$ premium above hybrid variety maize. Variety preferences in the ECLC results match anecdotal evidence of local variety preference from Smale et al. [32] who hypothesize that higher local variety prices could arise from decreased relative costs of storage. Lunduka et al. [33] provide recent evidence that consumers in Malawi prefer local maize varieties due to their perceived taste, storability, and high flour to grain ratios relative to hybrid varieties. Base MNL results are also presented for comparison. Driven by non-attendance to the price attribute, the MNL model would naïvely predict de-facto market rejection of all mold and insect damage levels. Discussions with traders and market observation clearly indicate this is not the case. The ECLC results are thus superior in terms of goodness-offit as well as providing significantly more realistic WTP estimates.

We find all significant WTP estimates for grain damage discounts are negative and ordinal, demonstrating that traders can distinguish physical attributes and there is a distinct price difference between grain damage levels ${ }^{7}$. Insect damage causes disutility, and the disutility increases with the intensity of insect damage ${ }^{8}$. Estimates from the ECLC model indicate that traders discount maize with $10 \%$ insect damage by $36 \%$ which translates to a discount schedule of approximately $3.6 \%$ price discount per $1 \%$ insect damaged grain (IDG) when the trader is not storing the grain. When insect damage is $20 \%$ or $30 \%$, the discount per $1 \%$ IDG is lower at $3.3 \%$ and $2.8 \%$ respectively, again assuming traders are not storing the grain that they are purchasing. Mold damage at $5 \%$ of grain causes more disutility than insect damage at $10 \%$ of grain.

One important factor which traders must consider when purchasing maize is the expected storage period before re-sale. Traders are asked to report their average storage time between purchase and resale. Among surveyed traders, 56\% store grain for a week or less before resale in the lean season while another $15 \%$ store grain for a month or more. All interaction variables between insect damage and trader storage time before resale are negative and significant. A trader who plans to store 10\% IDG maize for one month before resale will discount the grain $13 \%$ more than another trader who plans to sell immediately. The additional damage discount for grain to be stored is expected because damaged grain does not store as well as undamaged grain.

For completeness, standard LCM results are presented in Appendix, including coefficients and WTP estimates. The premiums and discounts for the maize attributes esti-

\footnotetext{
${ }^{7}$ Traders who can sell damaged grain as livestock feed may place higher valuation on damaged grain than other traders who lack access to these markets. However, we do not believe that this sort of selection bias is a major issue in our context for three reasons. First, the livestock sector in most animals that are grown for home consumption in Malawi are free range and fed on grass. Second, Jayne et al. [46] estimate that after an average harvest in Malawi only 30,000 out of nearly 426,000 metric tons (7\%) of marketed maize is purchased by the livestock and beer brewing industries combined. Third, Jayne et al. [46] also indicate that most industrial animal feeders and processors purchase maize from estate farms and large-scale traders. Estate farms and large-scale traders generally do not participate in the rural markets we surveyed, although large-scale traders may buy from small-scale traders in these rural markets.

${ }^{8} \mathrm{~A}$ broader graphical demonstration of trader ability to differentiate between damage levels based on marginal utility kernel densities [48] also confirms these results. Available from the author upon request.
} 
mated by the LCM, which are qualitatively consistent with the ECLC estimates, are also much larger than discounts generally observed in the market. The larger than expected discounts are hypothesized to stem from non-attendance of the price attribute, thus motivating the preference for the ECLC model'.

\section{Conclusions}

This article contributes to the literature by estimating the price discounts for insect damage in African rural maize markets. Malawi is selected as the case study for the East and Southern African region because of the single growing season, large seasonal variation in prices and presence of larger grain borer, as destructive insect that can potentially decimate maize in storage. WTP estimates for maize characteristics from 252 maize traders are elicited through a choice experiment (CE) using physical samples of maize. Several challenges exist with the use of $\mathrm{CE}$ in developing countries, including presentation of products and the navigating the complexity implementing experiments in the field. Increased attention has been placed recently on the application of choice modeling for low income respondents and in developing country contexts, including research protocols and experimental design and implementation [51].

The key results from the maize CE are as follows. First, we find traders discount maize with insect and mold damage and these discounts are statistically significant and economically important. Some countries in East Africa have published official discount schedules for parameters including IDG. However, there is little evidence to suggest that these discount schedules are used in rural markets across the region where most transactions are negotiated bilaterally in high frequency and low volumes. This article helps to better document the marketing reality of the smallholder farmer where the traders discount damaged grain but these discounts are not transparent to the farmer. In this regard, establishing clear standards for grain quality is considered an important step to improve grain markets in sub-Saharan Africa [12].

Second, we find that traders' preferences for maize quality attributes are well behaved. We find that traders who intend to store the maize before resale discount insect damage more severely than traders who intend to resell immediately. Consistent with Smale et al. [32] and Lunduka et al. [33], we find that traders in Malawi generally prefer local variety maize, while some sub-groups show significant preference for hybrid variety. Traders' subjective evaluation of mold and insect damage levels is of great importance to Malawian farmers considering investing in storage technologies. If the market does not reward quality, then the value of such investments is only in preventing weight loss. Results indicate that traders can visually distinguish levels of physical attributes, as

${ }^{9}$ The relative magnitude of the price coefficient increases dramatically in the ECLC model relative to the LCM model, decreasing WTP discount estimates by more than two-thirds. While only Class 2 had a significant price coefficient in the four-class LCM model, significant WTP estimates are possible for Class 1, 2, and 3. WTP estimates are not interpreted for Class 4, for which all coefficients are insignificant. The LCM, however, estimates classes 1 and 2 severely discount $10 \%$ IDG at over 50\%, and class 2 discounts $20 \%$ IDG at 70\%. The marginal discount for each $1 \%$ IDG is in excess of $5 \%$, about 7 -fold higher than the $0.75 \%$ price reduction for each $1 \%$ of IDG reported by Compton et al. [19]. The larger than expected discounts are hypothesized to stem from non-attendance of the price attribute. 
there are distinct utility and WTP coefficients for respective insect grain damage levels.

Third, this article also uses the ECLC method to treat significant non-attendance of the price attribute. The resulting ECLC WTP estimates are more consistent with observed market premiums and discounts and suggest that the WTP discounts and premiums in the LCM model that are not corrected for price non-attendance are greatly overestimated.

This article thus offers insight into the maize quality premiums and discounts which are overlooked in the post-harvest literature for developing countries. The value of publicly-available and transparent discount schedules that reflect market realities is to align farmer incentives with buyer preferences because farmers understand the economic consequences of insect and mold damage. Furthermore, discount schedules offer farmers a financial incentive to invest in storage technologies and practices that reduce insect and mold damage, which would improve maize quality overall. If a farmer has maize that has insect and mold damage which will increase over time, discount schedules also provide a strong financial signal to farmers to deliver the grain immediately rather than storing and delivering later at a large discount. Future research might expand and connect regional insect and mold discounts in relevant sales outlets to smallholder post-harvest management and marketing decisions. Future work might also directly compare CE data for quality premiums and discounts with non-hypothetical methods such as hedonic price analysis and experimental auctions. Future work that considers farmers' willingness-to-accept payment for damaged maize is also important, and would complement this article's focus on the traders' perspective.

\section{References}

[1] World Bank (2011) Missing Food: The Case of Postharvest Grain Losses in Sub-Saharan Africa. Report 60371-AFR.

[2] Dick, K. (1988) A Review of Insect Infestation of Maize in Farm Storage in Africa with Special Reference to the Ecology and Control of Prostephanustruncatus. Natural Resources Institute, Bulletin No. 18. NRI, Chatham Maritime, Kent ME4 4TB, UK.

[3] Golob, P. and Hanks, C. (1990) Protection of Farm Stored Maize against Infestation by Prostephanustruncatus (Horn) and Sitiphilus Species in Tanzania. Journal of Stored Products Research, 26, 187-198. http://dx.doi.org/10.1016/0022-474X(90)90021-J

[4] Renkow, M. (1990) Household Inventories and Marketed Surplus in Semisubsistence Agriculture. American Journal of Agricultural Economics, 72, 664-675. http://dx.doi.org/10.2307/1243036

[5] Saha, A. and Stroud, J. (1994) A Household Model of On-Farm Storage under Price Risk. American Journal of Agricultural Economics, 76, 522-534. http://dx.doi.org/10.2307/1243663

[6] Park, A. (2006) Risk and Household Grain Management in Developing Countries. The Economic Journal, 116, 1088-1115. http://dx.doi.org/10.1111/j.1468-0297.2006.01124.x

[7] Stephens, E. and Barrett, C. (2011) Incomplete Credit Markets and Commodity Marketing Behavior. Journal of Agricultural Economics, 62, 1-24. http://dx.doi.org/10.1111/j.1477-9552.2010.00274.x

[8] Jones, M., Alexander, C. and Lowenberg-DeBoer, J. (2014) A Simple Methodology for 
Measuring Profitability of On-Farm Storage Pest Management in Developing Countries. Journal of Stored Products Research, 58, 67-76. http://dx.doi.org/10.1016/j.jspr.2013.12.006

[9] Hoffman, V. and Gatobu, K.M. (2014) Growing Their Own: Unobservable Quality and the Value of Self-Provisioning. Journal of Development Economics, 106, 168-178. http://dx.doi.org/10.1016/j.jdeveco.2013.08.006

[10] Kadjo, D., Ricker-Gilbert, J. and Alexander, C. (2016) Estimating Price Discounts for LowQuality Maize in Sub-Saharan Africa: Evidence from Benin. World Development, 77, 115 128. http://dx.doi.org/10.1016/j.worlddev.2015.08.004

[11] Hill, L.D. (1990) Grain Grades and Standards: Historical Issues Shaping the Future. University of Illinois Press, Urbana Champaign.

[12] Jayne, T.S., Chapoto, A. and Govereh, J. (2007) Grain Marketing Policy at a Crossroads: Challenges for Eastern and Southern Africa. Paper Prepared for the FAO Workshop on "Staple Food Trade and Market Policy Options for Promoting Development in Eastern and Southern Africa", Rome, 1-2 March 2007.

[13] Hodges, R.J., Buzby, J.C. and Bennett, B. (2011) Postharvest Losses and Waste in Developed and Less Developed Countries: Opportunities to Improve Resource Use. Journal of Agricultural Science, 149, 37-45. http://dx.doi.org/10.1017/S0021859610000936

[14] FAO Agricultural Statistics Database (FAOSTAT) (2011) http://faostat.fao.org/site/368/DesktopDefault.aspx?PageID=368\#ancor

[15] Chapoto, A.C. and Jayne, T.S. (2010) Maize Price Instability in Eastern and Southern Africa: The Impact of Trade Barriers and Market Interventions. Prepared for the COMESA Policyseminar on "Variation in Staple Food Prices. Causes, Consequences, and Policy Options", Maputo, 25-26 January 2010.

[16] Mishili, F.J., Temu, A., Fulton, J. and Lowenberg-DeBoer, J. (2011) Consumer Preferences as Drivers of the Common Bean Trade in Tanzania: A Marketing Perspective. Journal of International Food \& Agribusiness Marketing, 23, 110-127. http://dx.doi.org/10.1080/08974438.2011.558761

[17] Langyintuo, A.S., Ntoukam, G., Murdock, L., Lowenberg-DeBoer, J. and Miller, D.J. (2004) Consumer Preferences for Cowpea in Cameroon and Ghana. Journal of Agricultural Economics, 30, 203-213. http://dx.doi.org/10.1111/j.1574-0862.2004.tb00189.x

[18] Mishili, F.J., Fulton, J., Shehu, M., Kushwaha, S., Marfo, K., Jamal, M., Chergna, A. and Lowenberg-DeBoer, J. (2009) Consumer Preferences for Quality Characteristics along the Cowpea Value Chain in Nigeria, Ghana, and Mali. Agribusiness, 25, 16-35.

[19] Compton, J.A.F., Floyd, S., Magrath, P.A., Addo, S., Gbedevi, S.R., Agbo, B., Bokor, G., Amekupe, S., Motey, Z., Penni, H. and Kumi, S. (1998) Involving Grain Traders in Determining the Effect of Post-Harvest Insect Damage on the Price of Maize in African Markets. Crop Protection, 17, 483-489. http://dx.doi.org/10.1016/S0261-2194(98)00041-6

[20] Hoffman, V., Mutiga, S., Harvey, J., Nelson, R. and Milgroom, M. (2013) Asymmetric Information and Food Safety: Maize in Kenya. 2013 Annual Meeting of Agricultural and Applied Economics Association, Washington DC, 4-6 August 2013.

[21] Lusk, J., Roosen, J. and Fox, J. (2003) Demand for Beef from Cattle Administered Growth Hormones or Fed Genetically Modified Corn: A Comparison of Consumers in France, Germany, the United Kingdom, and the United States. American Journal of Agricultural Economics, 85, 16-29. http://dx.doi.org/10.1111/1467-8276.00100

[22] Rigby, D. and Burton, M. (2005) Preference Heterogeneity and GM food in the UK. European Review of Agricultural Economics, 32, 269-288.

http://dx.doi.org/10.1093/eurrag/jbi009 
[23] Lancaster, K.J. (1966) A New Approach to Consumer Theory. Journal of Political Economy, 74, 132-157. http://dx.doi.org/10.1086/259131

[24] Wolf, C.A., Tonsor, G.T. and Olynk, N.J. (2011) Understanding U.S. Consumer Demand for Milk Production Attributes. Journal of Agricultural and Resource Economics, 36, 326-342.

[25] Lusk, J.L, Norwood, F.B. and Pruitt, J.R. (2006) Consumer Demand for a Ban on Antibiotic Drug Use in Pork Production. American Journal of Agricultural Economics, 88, 1015-1033. http://dx.doi.org/10.1111/j.1467-8276.2006.00913.x

[26] Oretga, D., Wang, H., Wu, L. and Olynk, N. (2011) Modeling Heterogeneity in Consumer Preferences for Select Food Safety Attributes in China. Food Policy, 36, 318-324. http://dx.doi.org/10.1016/j.foodpol.2010.11.030

[27] Su, L., Adam, B., Lusk, J. and Arthur, F. (2011) A Comparison of Auction and Choice Experiment: An Application to Consumer Willingness to Pay for Rice with Improved Storage Management. 2011 Annual Meeting, Pittsburgh, 24-26 July 2011.

[28] Holst, N., Meikle, W.G. and Markham, R.H. (2000) Grain Injury Models for Prostephanustruncatus (Coleoptera: Bostrichidae) and Sitophilus zeamis (Coleoptera: Curculionidae) in Rural Maize Stores in West Africa. Journal of Economic Entomology, 93, 1338-1346. http://dx.doi.org/10.1603/0022-0493-93.4.1338

[29] Adda, C., Borgemeister, C., Biliwa, A., Meikle, W.G., Markham, R.H. and Peohling, H.M. (2002) Integrated Pest Management in Post-Harvest Maize: A Case Study from the Republic of Togo (West Africa). Agriculture, Ecosystems, \& Environment, 93, 305-321. http://dx.doi.org/10.1016/S0167-8809(01)00344-9

[30] Meikle, W.G., Markham, R.H., Nansen, C., Holst, N., Degbey, P., Azoma, K. and Korie, S. (2002) Pest Management in Traditional Maize Stores in West Africa: A Farmer's Perspective. Journal of Economic Entomology, 95, 1079-1088.

[31] De Groote, H., Kimenju, S.C., Likhayo, P., Kanampiu, F., Tefera, T. and Hellin, J. (2013) Effectiveness of Hermetic Systems in Controlling Maize Storage Pests in Kenya. Journal of Stored Products Research, 53, 27-36. http://dx.doi.org/10.1016/j.jspr.2013.01.001

[32] Smale, M., Heisey, P.W. and Leathers, H.D. (1995) Maize of the Ancestors and Modern Varieties: The Microeconomics of High-Yielding Variety Adoption in Malawi. Economic Development and Cultural Change, 43, 351-368. http://dx.doi.org/10.1086/452154

[33] Lunduka, R., Fisher, M. and Snapp, S. (2012) Could Farmer Interest in Diversity of Seed Attributes Explain Adoption Plateaus for Modern Varieties in Malawi? Food Policy, 37, 504-510. http://dx.doi.org/10.1016/j.foodpol.2012.05.001

[34] Greene, W.H. (2003) Econometric Analysis. 5th Edition, Prentice Hall, Upper Saddle River.

[35] Hole, A.R. (2007) A Comparison of Approaches to Estimating Confidence Intervals for Willingness to Pay Measures. Health Economics, 16, 827-840. http://dx.doi.org/10.1002/hec.1197

[36] Tonsor, G.T., Schroeder, T.C., Fox, J.A. and Biere, A. (2005) European Preferences for Beef Steak Attributes. Journal of Agricultural and Resource Economics, 30, 367-380.

[37] Olynk, N.J., Tonsor, G.T. and Wolf, C.A. (2010) Consumer Willingness to Pay for Livestock Credence Attribute Claim Verification. Journal of Agricultural and Resource Economics, 35, 261-280.

[38] Manski, C.F. (1977) The Structure of Random Utility Models. Theory and Decision, 8, 229254. http://dx.doi.org/10.1007/BF00133443

[39] Revelt, D. and Train, K. (1998) Mixed Logit with Repeated Choices: Households' Choices of Appliance Efficiency Level. The Review of Economics and Statistics, 80, 647-657. 
http://dx.doi.org/10.1162/003465398557735

[40] Train, K.E. (2003) Discrete Choice Methods with Simulation. Cambridge University Press, Cambridge. http://dx.doi.org/10.1017/CBO9780511753930

[41] Boxall, P.C. and Adamowicz, W.L. (2002) Understanding Heterogeneous Preferences in Random Utility Models: a Latent Class Approach. Environmental and Resource Economics, 23, 421-446. http://dx.doi.org/10.1023/A:1021351721619

[42] Scarpa, R., Gilbride, T.J., Campbell, D. and Hensher, D.A. (2009) Modeling Attribute NonAttendance in Choice Experiments for Rural Landscape Valuation. European Review of Agricultural Economics, 36, 151-174. http://dx.doi.org/10.1093/erae/jbp012

[43] Hensher, D. and Greene, W. (2010) Non-Attendance and Dual Processing of CommonMetric Attributes in Choice Analysis: A Latent Class Specification. Empirical Economics, 39, 413-426. http://dx.doi.org/10.1007/s00181-009-0310-x

[44] National Statistics Office (NSO), Republic of Malawi (2008) 2008 Population and Housing Census, Preliminary Report. National Statistics Office, Zomba, Malawi, September 2008.

[45] Ministry of Agriculture and Food Security (2009) Agricultural Input Subsidy Survey II (AISS2). Lilongwe, Malawi.

[46] Jayne, T.S., Sitko, N., Ricker-Gilbert, J. and Mangisoni, J. (2010) Malawi's Maize Marketing System. Paper Prepared for Malawi's Ministry of Agriculture and Food Security, 6 February 2010.

[47] Lusk, J. and Fox, J.A. (2003) Value Elicitation in Laboratory and Retail Environments. Economics Letters, 79, 27-34. http://dx.doi.org/10.1016/S0165-1765(02)00284-7

[48] Hess, S. and Hensher, D.A. (2010) Using Conditioning on Observed Choices to Retrieve Individual-Specific Attribute Processing Strategies. Transportation Research Part B: $\mathrm{Me}$ thodological, 44, 781-790. http://dx.doi.org/10.1016/j.trb.2009.12.001

[49] Widmar, N.J.O. and Ortega, D.L. (2014) Comparing Consumer Preferences for Livestock Production Process Attributes Across Products, Species, and Modeling Methods. Journal of Agricultural and Applied Economics, 46, 375-391.

[50] Jones, M., House, L.A. and Gao, Z. (2015) Respondent Screening and Revealed Preference Axioms: Testing Quarantining Methods for Enhanced Data Quality in Web Panel Surveys. Public Opinion Quarterly, 79, 687-709. http://dx.doi.org/10.1093/poq/nfv015

[51] Bennett, J. and Birol, E. (2010) Choice Experiments in Developing Countries: Implementation, Challenges and Policy Implications. Edward Elgar, Cheltenham.

http://dx.doi.org/10.4337/9781781000649 


\section{Appendix: Malawian Trader Latent Class Model Coefficients and WTP for Maize Quality} Attributes.

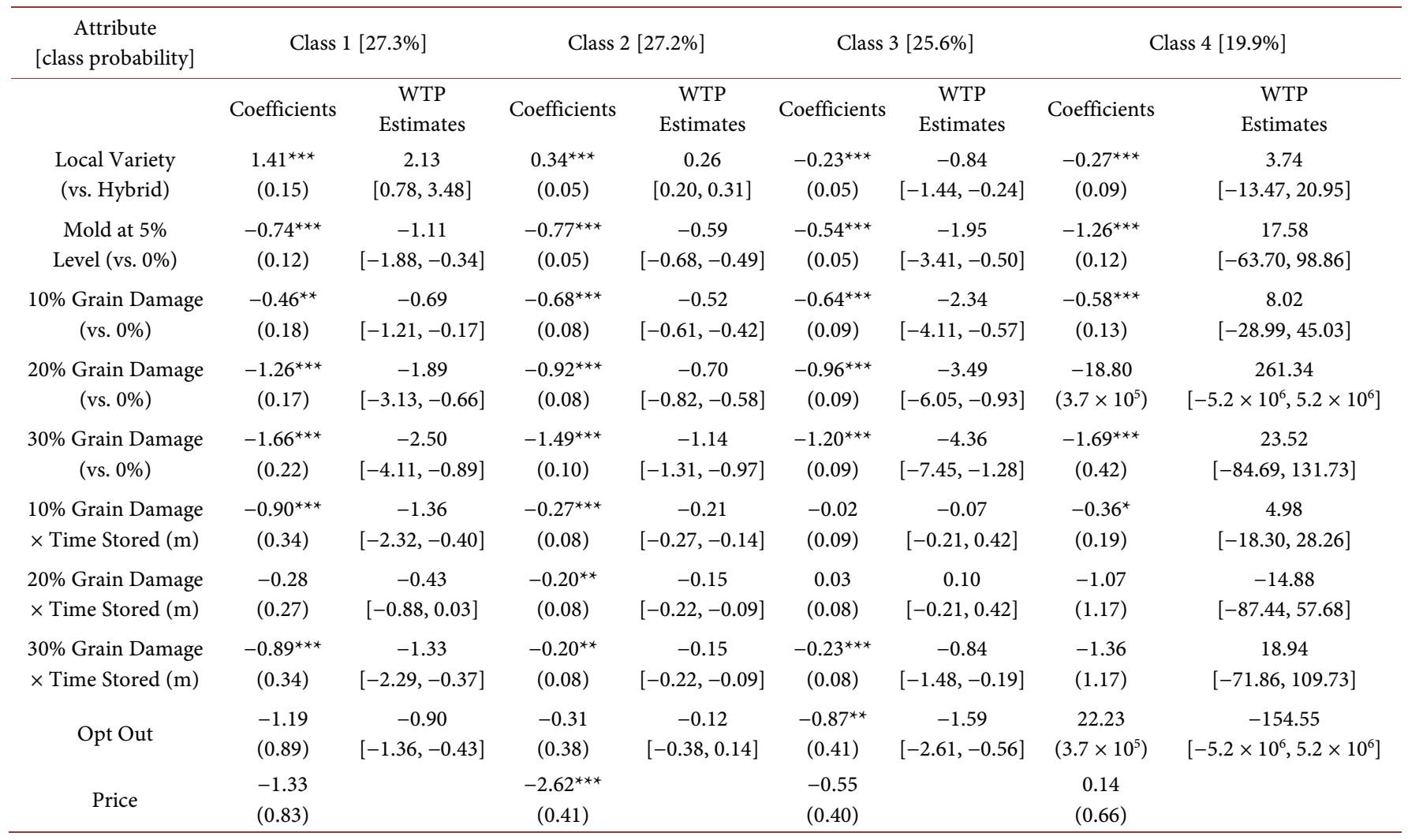

Note: Log-likelihood -1808.31; Pseudo- $\mathrm{R}^{2}$ 0.347. Note: Standard errors are presented in parenthesis below parameter estimates. Note: ${ }^{*},{ }^{* *}$ and ${ }^{* * *}$ indicate significance at the $10 \%, 5 \%$, and $1 \%$ level, respectively. for you:

Accepting pre-submission inquiries through Email, Facebook, LinkedIn, Twitter, etc.

A wide selection of journals (inclusive of 9 subjects, more than 200 journals)

Providing 24-hour high-quality service

User-friendly online submission system

Fair and swift peer-review system

Efficient typesetting and proofreading procedure

Display of the result of downloads and visits, as well as the number of cited articles

Maximum dissemination of your research work

Submit your manuscript at: http://papersubmission.scirp.org/

Or contact me@scirp.org 